For reprint orders, please contact: reprints@futuremedicine.com

\title{
Aging successfully
}

\section{John E Morley speaks to Natasha Leeson, Commissioning Editor}

John E Morley completed his medical degree at the University of Witwatersrand in Johannesburg (South Africa) in 1972. After completing his internal medicine residency in South Africa he completed a fellowship in endocrinology at University of California, Los Angeles (CA, USA). He was subsequently a staff endocrinologist at the Minneapolis VA Medical Center (MN, USA) and the University of Minnesota (MN, USA). In January 1985, he moved to California to become Director of the Geriatric Research, Education, and Clinical Center, Sepulveda VA Medical Center (CA, USA) and a Professor of Medicine at University of California, Los Angeles. He is board certified in internal medicine, endocrinology and geriatric medicine. He has published over 900 papers, with a major research emphasis on the role of neuropeptides in the modulation of hormonal responses and behavior as well as nutrition and hormones in older persons. For his work in appetite regulation, he received the Mead Johnson Award of the American Institution of Nutrition in 1985. He was among the 100 most-cited authors in the world from 1980 to 1988. He was the Medical Director of the Year for Life Care Centers of America (TN, USA) in 1998. In 1999, he was awarded the IPSEN Foundation Longevity Prize, which is one of the most prestigious European awards for research in gerontology. In 2002, he was chosen to receive the American Geriatrics Society's Nascher/Manning Award for his life-long achievements in clinical geriatrics. In 2003, he became a Fellow in the Gerontological Society of America. He has served on the editorial boards of nine journals and, since 2007, he is the Editor-in-Chief of JAMDA. He has been an invited speaker at numerous national and international meetings. In July 1989, Dr Morley moved to St Louis (MO, USA), to become the Dammert Professor of Gerontology and Director, Division of Geriatric Medicine at Saint Louis University Medical Center and Director of the Geriatric Research, Education, and Clinical Center at the Saint Louis Veterans Affairs Medical Center. He is the Medical Director of six nursing and/or assisted living homes.

\section{- How did your career lead you to a profession in geriatrics?}

It was more of a coincidence than anything else. I was practicing as an endocrinologist in Minnesota (USA), and I decided that I needed to go anywhere where it was not as cold as it was in Minnesota. I found a job at The University of California, Los Angeles (UCLA; CA, USA); they wanted someone to run the geriatric research and education unit. I took the job, and that's how I became a geriatrician. I absolutely adore geriatrics now but, at the time, I don't think I even knew what geriatrics was.

What do you consider to be the biggest achievement in your career so far?

It is difficult to pick one thing; however, developing the geriatrics program at Saint Louis University (MO, USA) was certainly a major achievement. This was one of the first major geriatrics programs in midwest USA. Although I have completed multiple pieces of research in this field, I think the program will long outlast any of the research that I have conducted.

- Of your research, what would you say

has had the largest clinical impact?

There are two pieces of research that stand out for me. First, was developing the concept of anorexia in aging. I based this on Cicero's idea that he was grateful to old age because, as he aged, he found that he was more interested in good conversation and less interested in good food. Using science research, I was able to demonstrate why this happens. More recently, I have been working on antisenses to help treat Alzheimer's disease, which I think are very exciting.

\section{- What do you think are the most important factors to consider when treating elderly individuals?}

I think the most important thing is to recognize that older individuals are different from their younger counterparts; as such, polypharmacy is a huge issue. We have a tendency, certainly in the USA and to a lesser extent in Europe, to overtreat the elderly with drugs. These drugs have a very small effect in middle-aged individuals, but are more likely to cause side effects in elderly individuals than actually cure them. Consequently, prescribing exercise therapy in this population is probably more important than anything else we can offer patients. Exercise programs, specifically designed for elderly individuals, need to be further implemented.
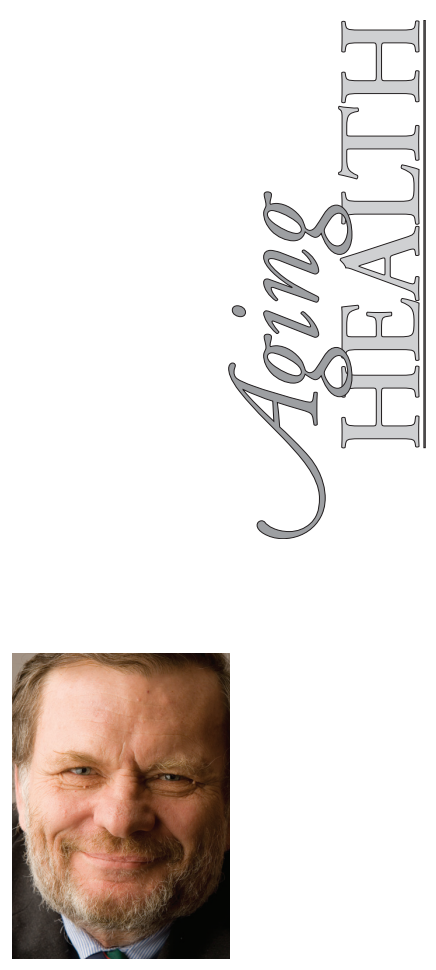

John E Morley

Divisions of Geriatric Medicine \& Endocrinology, Saint Louis University, Saint Louis, MO, USA morley@slu.ed

\section{Keywords}

- Alzheimer's disease $\bullet$ anorexia - delirium • frailty $\bullet$ nursing home

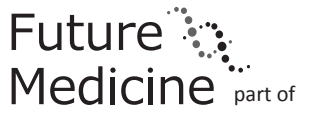


- Do you prescribe exercise to your patients? Do you see a benefit in these patients following exercise?

Yes, I write exercise prescriptions for my elderly patients and those who do the exercise seem to benefit. The literature supports that there are major benefits of exercise; for example, it improves thought processes, reduces depression and sarcopenia, and increases strength and cardiovascular function. I don't think there is any question that exercise is the single best treatment available for older individuals.

- Do you think it is important to consider frailty when treating the elderly? Should all elderly individuals be routinely screened for it?

We recently put out a statement from the consensus conference, which I jointly chaired with Bruno Vellas from Toulouse (France). In this we state that treating frailty is central to stopping disability and death in older individuals. The consensus conference said that everyone over the age of 70 years should be screened for frailty using a simple questionnaire, such as the Frail Questionnaire, and that frail individuals should have a targeted approach to their treatment, so that each component of frailty is individually addressed.

How do you propose that we implement this? Should individuals be screened as soon as they turn 70 years of age?

It could be earlier than 70 years of age, my colleagues and I chose 70 years because we thought it was the most feasible. However, we have conducted studies in elderly inner-city African-American individuals at an earlier age. The frail screen is just questions such as: are you fatigued? Can you walk up a flight of stairs? How many illnesses have you got? Therefore, it is a very quick and easy screen that can be performed by any physician. If the patient answers yes to three or more of the questions, they should be referred to a geriatrician for further assessment.

\section{How can we best meet the needs of elderly residents in nursing homes?}

Based on the International Association of Gerontology and Geriatrics (IAGG) consensus conference, I think that nursing homes should have a medical presence. When I recently conducted a survey, approximately a third of nursing homes worldwide have a physician involved in the administration. I think it is extraordinarily important to have a physician working in collaboration with a nurse and a social worker/administrator to improve quality of care in nursing homes. Furthermore, there should be increased research in nursing homes; in particular, there should be a focus on testing drugs in nursing home residents. Finally, I felt that there should be a national education program; consequently, I developed the IAGG certificate and course book for nursing homes to help improve education. I feel that education is just as important as research, and both need to be implemented together. This will help to improve care in nursing homes.

Overall, there should be a focus, not only on nursing homes, but also on aging at home - do elderly individuals always need to go into a nursing home? Are there ways that will allow them to live at home? Technology developments, particularly robotics, will make a major difference in our ability to look after older individuals in nursing homes and allow them to live independently at home.

\section{- Do you think it is possible to give the best quality of care when many elderly patients have comorbidities, \& even multimorbidities, such as delirium?}

Delirium, if appropriately approached, can be a very treatable condition. Multimorbidity is an issue that leads to polypharmacy, which probably leads to more problems than anything else. In the USA, the tendency is to treat everything that the elderly patient has, resulting in vast quantities of drugs that an individual needs to take. I think that much of the morbidity related to multimorbidity is actually due to the treatment, or overtreatment, of these conditions. Instead, we should look at treating the conditions that most affect quality of life and leave the others alone.

\section{- There is a lot reported in the media} about the care \& quality of life provided in nursing homes. Is this the same worldwide? Is it justified?

Nursing homes tend to get a bad press everywhere since it is very easy to say they are terrible. In the USA, I believe the quality of care in nursing homes is as good, if not better, than in hospitals. I understand that in the UK, where there is very little medical input in nursing homes, there are some real problems. There has been some attempt by individuals, such as Finbar Martin, to improve the care in the medical side of nursing homes, which I think is an important component. 
The education for physicians on nursing care homes in the USA, conducted predominately by the American Medical Directors Association, is superb. The work that the IAGG has started to carry out in education is also a great step forward. This doesn't mean that nursing homes in the UK and Europe are not as good as those in the USA; it is just that the overall quality is somewhat better in the USA because of the education and regulations. Nursing homes are very highly regulated in the USA. This is because in 1988, the Office of Budget Reconciliation Act was introduced in the USA to improve nursing homes. It must be remembered that nursing homes are first and foremost a home, therefore, the quality as a home needs to be answered in conjunction with providing medical care. I think the Dutch have done this extraordinarily well - they have nursing home doctors who work there full time and are trained specifically for that environment. As such, I think they have improved medical care in nursing homes, more than most other countries.

I know that people are trying to change nursing homes, for example, Bupa (London, UK) care homes. If attention is paid to the nursing home course that the IAGG has developed, hopefully they won't make as many mistakes as we made in the USA trying to get to where we are now.

\section{- There is currently a lot of discussion about individuals living for longer. Do you think we are suitably prepared for this?}

There are two points to consider here. First, the problem, particularly in the USA, has been a lack of enthusiasm for individuals specializing in geriatrics, possibly since it has lower pay than other specialties. Europe has recently gone a long way in increasing the pay for geriatric specialists and many countries are making geriatrics a much more popular area. We are very short of geriatricians worldwide, so governments need to put more emphasis on training more geriatricians. If this is not done, we will certainly feel the effects, as we will not be able to cope with the aging population. In the UK, geriatricians tend to be hospital focused and I think geriatricians need to be much more outpatient and nursing home focused. I think these are important changes if we are to be successful in caring for older individuals.

Second, increasing the general public's awareness of good behaviors, starting with exercise and eating healthily, are going to be extraordinarily important components to achieving a successful outcome. Understanding the differences between older individuals aged 70 years and older, for example, their physiology and how it interacts with disease, is going to become very important. Fortunately, people are healthier now than when I started geriatrics - back then, my patients were between 60 and 75 years of age and now the majority of my patients are in their 80s. Many individuals are still working well into their 70 s.

\section{- In your opinion, do you think the lack of individuals specializing in geriatrics is one of the biggest challenges we currently face in gerontology?}

You have to have people in the field to acquire research and we have a shortage of people in geriatrics, so there is a large amount of research that needs to be carried out. Consequently, we need more centers like the Toulouse Gérontopôle (France), which Bruno Vellas runs. We need large centers that work with the community family practitioners to slowly develop research in the community - this will be absolutely crucial to long-term outcomes.

\section{- How do you see research in geriatrics changing in the next 5-10 years?}

Geriatrics requires a much better understanding of the whole human being and looking at an individual as a psychosocial medical being, not just as someone whose life is related to their disease. Hopefully, we will see research breakthroughs in frailty. The development of good research studies that showing that early detection and treatment of frailty will make a big difference, and improving the treatment of dementia, with the discovery of drugs that will work alongside current treatment options, such as cognitive stimulus therapy, will also be important.

\section{Disclaimer}

The opinions expressed in this interview are those of the interviewee and do not necessarily reflect the views of Future Medicine Ltd.

Financial \& competing interests disclosure

$J$ Morley has no relevant affiliations or financial involvement with any organization or entity with a financial interest in or financial conflict with the subject matter or materials discussed in the manuscript. This includes employment, consultancies, honoraria, stock ownership or options, expert testimony, grants or patents received or pending, or royalties.

No writing assistance was utilized in the production of this manuscript. 